Journal of Computer Science and Cybernetics, V.26, N.4 (2010), 375-384

\title{
FUZZY BASED WELDING SEAM TRACKING CONTROL FOR GMAW WITH ROTATING ARC SENSOR
}

\author{
THANH LUAN NGUYEN, THIEN PHUC TRAN ${ }^{1}$, DUY ANH NGUYEN, TAN TIEN NGUYEN ${ }^{2}$ \\ ${ }^{1}$ Mechatronics Engineering Dept, Ho Chi Minh City University of Technology, Vietnam \\ *2Faculty of Mechanical Engineering, Ho Chi Minh City University of Technology, Vietnam
}

\begin{abstract}
This paper presents a rotating arc sensor model using Fast Fourier Transform to transform original welding current signal into frequency domain. We analyze spectrum of signal, eliminate unwanted frequencies and inverse transform signal into time domain. This signal was used to calculate input signal for the fuzzy logic controller to control a 2D table with two DC motors and two ball screws that carries a welding torch during the process of automatic seam tracking of arc welding. Input data of the controller is the deviation of average currents between the two half-cycles current corresponding to two half-cycles rotating of the torch on the left and right of centerline of the welding track. The controller were comprised of a regression model, expressing the relationship between the average current deviation and offset distance through weaving experiments. Finally, the direction and the speed of motors are calculated.
\end{abstract}

Tóm tắt. Bài báo này giới thiệu một mô hình cảm biến hồ quang quay sử dụng bộ lọc FFT để chuyển đổi tín hiệu dòng điện gốc trong miền thời gian sang miền tần số, phân tích phổ tín hiệu, loại đi thành phần tín hiệu không mong muốn và chuyển ngược về miền thời gian. Tín hiệu này được dùng để tính toán giá trị đầu vào cho bộ điều khiển mờ điều khiển một bàn máy hai trục vuông góc mang theo đầu hàn trong quá trình hàn tự động bám đường hàn. Tín hiệu vào của bộ điều khiển là độ lệch cường độ dòng điện hàn của hai nửa chu kỳ biến đổi dòng điện tương ứng với hai nửa chu kỳ quay bên trái và bên phải đường tâm rãnh hàn của đâu hàn. Dựa vào tín hiệu hồi tiếp, bộ điều khiển tính toán sự liên hệ giữa độ lệch cường độ dòng điện hàn và độ lệch đâu hàn trong rãnh hàn, cuối cùng chiều và tốc độ quay của động cơ được tính toán.

\section{INTRODUCTION}

In recent times, welding process is a difficult manufacturing process because of insufficiency of skilled workers as well as the decline of productivity and requirement of continuous and stable quality control. Robotic welding is widely adapted in several fields of welding shops for improvement of welding efficiency and liberating operators from severe working environment. In order to realize more compact and convenient automatic welding under complicate welding environment, an intelligent type of welding robot with ability of welding seam tracking is required[3]. Thus, seam tracking sensor becomes very important. The arc sensor has the advantages of compactness requiring no detectors around the welding torch, and of being unaffected by heat and arc light. The arc sensor weaves or rotates along the welding tip at an 
appropriate speed according to various welding conditions and uses electrical signal obtained from welding arc itself. The seam tracking is performed by using current patterns changed according to variation of the arc length distance on one weaving or rotating cycle. In spite of welding smog, arc light and spatter, the arc sensor can precisely achieve seam tracking and lead to a satisfactory welding bead. Moreover, it does not need a special detection device attached to the torch and its production cost is comparatively very low because it is developed by software based on arc characteristics[3].

In this paper, a 2D table experiment model uses FFT (Fast Fourier Transform) to analyze spectrum of current signal and fuzzy logic controller, which is developed to adjust the position of the torch to match the centerline of V-groove based on rotating arc sensor.

\section{MATHEMATICAL MODEL OF ROTATIONAL ARC SENSOR}

\subsection{Principle of Arc sensor}

In GMAW, welding current and the arc length had the closed relationship. Specifically, if the arc length increase, welding current will decrease, and welding current will increase if the arc length decreases. Fig.1 shows the principle of arc sensor. When the torch moves from position no.1 to position no.3, the arc length decrease and the welding current increase (the curve 123 on Fig.1). When the torch moves from position no.3 to position no.4, position no.5 and position no.1, the arc length decreases and the welding current increases. So, according to welding current signal we can determine the position of the torch on the welding groove.

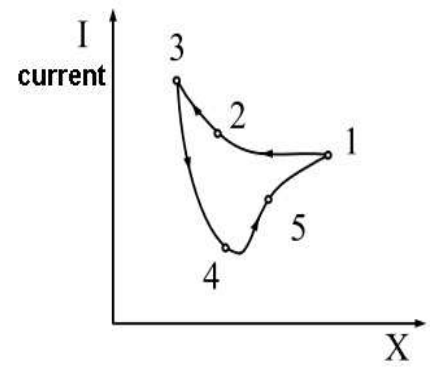

Figure 1. Principle of Arc Welding

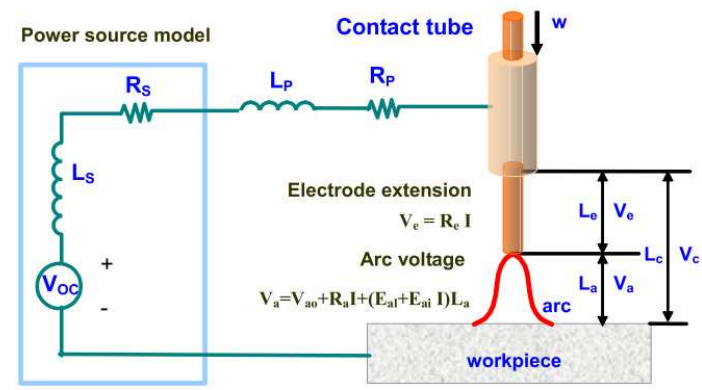

Figure 2. Equivalent Circuit of GMAW System

\subsection{Rotating Arc sensor}

In GMAW with consumable wire electrodes, power sources with a constant potential characteristic is employed. Fig.2 shows the equivalent circuit of a GMAW system. The resistance at wire extension $R_{e}$ can be calculated as

$$
R_{e}=\frac{V_{e}}{I}=\frac{a L_{e}}{S}-\frac{b w S}{I^{2}},
$$

where $V_{e}$ is the voltage across the wire extension, $a$ is a constant equal to the high temperature resistivity of the wire extension $(\Omega . \mathrm{mm}), b$ is a constant depending on the room temperature resistivity of the wire, $L_{e}$ is the wire extension, $w$ is the wire feed rate, $I$ is the welding current 

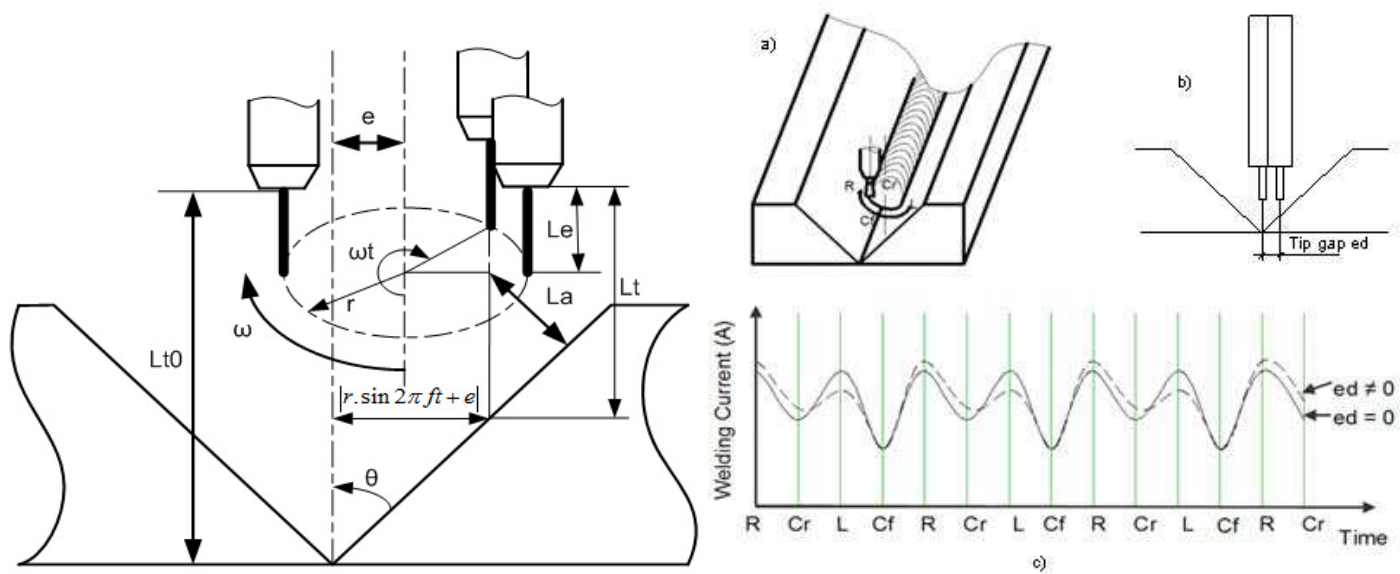

Figure 3. Model of arc length

Figure 4. Welding model and correspondent current

and $S$ is cross section area of the wire. Then, the wire extension and welding current during GMAW are given

$$
\frac{d L_{e}}{d t}=w-\frac{A I}{1-\frac{B L_{e} I^{2}}{w}}
$$

and

$$
\frac{d I}{d t}=\frac{V_{o c}-V_{a 0}}{L_{s}+L_{p}}-\frac{R_{s}+R_{p}+R_{a}+R_{e}}{L_{s}+L_{p}} I-\frac{E_{a l}+E_{a i} I}{L_{s}+L_{p}} L_{a}
$$

where, $A=\phi /\left[S\left(H_{0}+b\right)\right]$ and $B=a /\left[\left(S^{2}\left(H_{0}+b\right)\right)\right], F$ is the equivalent arc voltage for wire melting phenomenon, $H_{0}$ is the heat content per unit volume of droplet received at detachment, $V_{o c}, R_{s}$ and $L_{s}$ are the internal voltage, electrical resistance and inductance of the welding power source, respectively. $V_{p}, R_{p}$, and $L_{p}$ are the voltage drop, the resistance and the inductance of the welding cable, respectively. $V_{a 0}$ is a constant in the welding model. $R_{a}$, $L_{a}$ and $\left(E_{a l}+E_{a i} I\right)$ are the resistance, the length and the electric field of the arc, respectively.

The arc length can be calculated by (Fig.3):

$$
L_{a}=\left(L_{t 0}-\frac{|r \cdot \sin (2 \pi f t)+e|}{\operatorname{tg} \theta}-L_{e t}\right) \cdot \sin \theta
$$

Fig.4 shows a relation of welding current and weaving direction and the cross-section of the V-groove welding and their corresponding current waveforms with a centered or offset rotating torch. The maximum welding currents at the left and right half cycles are equal, when the torch is in centered position $\left(e_{d}=0\right)$. While the welding torch is deviated from the angle bisector of the $\mathrm{V}$ groove, the current waveform changes. If the torch is on the left of centerline, average welding current of left haft cycle is larger than average welding current of right haft cycle, and the difference between them $\left(I_{\text {left }}-I_{\text {right }}\right)$ is used for the torch offset detecting during seam tracking. 


\section{EXPERIMENT SYSTEM}

\subsection{Design of experiment model}

In this paper, we developed a 2D table experiment model with two DC motor, two ball screws. The slider carried rotator and welding tip. Fig.5 shows block diagram of experiment model.
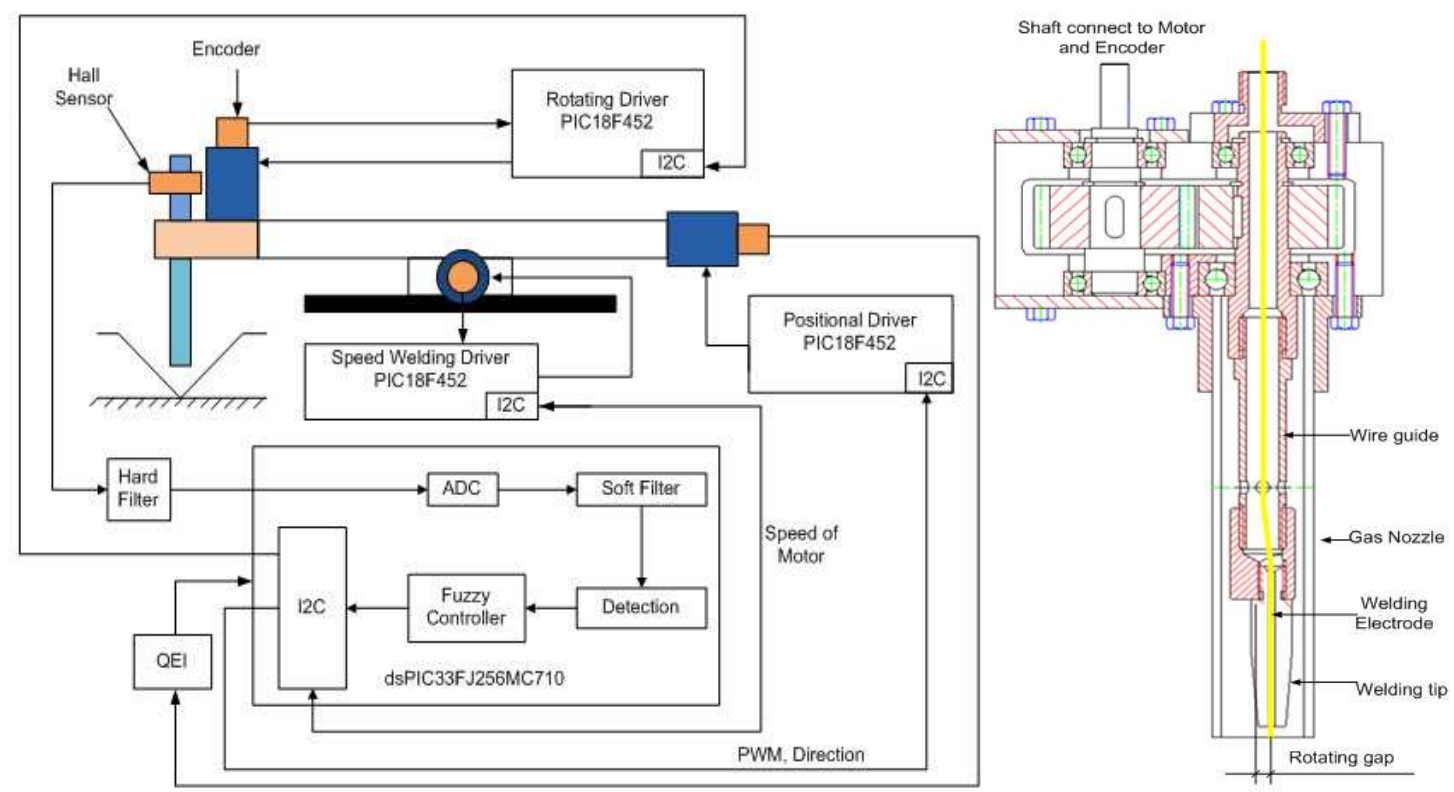

Figure 5. Block diagram of experiment model

Figure 6. Geometry of Rotator

\subsection{Data acquisition and processing}

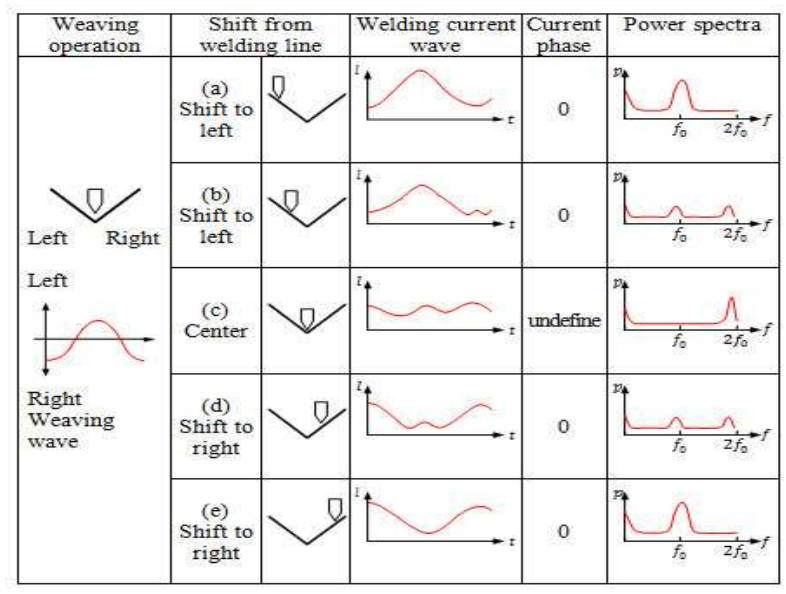

Figure \%. Welding current spectrum[1]

Fig. 5 shows the data acquisition model. The Hall current sensor measure welding current signal and transfer to voltage signal. Because the output voltage of Hall sensor is the analog 
signal containing noise and interference, we use the low pass filter to eliminate high frequency interference and noise. Therefore, microprocessor will sample and convert to digital signal. Finally, we use the soft filter to obtain the desired signal, which uses to calculate the control signal. Fig. 7 shows the welding current spectrum of welding current wave when the welding torch rotates stably at frequency $f_{0}$, power spectra of welding current wave at frequency $f_{0}$ and $2 f_{0}$ are higher than power spectra of others. So, we can use FFT filter to eliminate interference which has frequency greater than $2 f_{0}[1]$.

\subsubsection{Hard filter}

Because rotation frequency of the torch is $20 \mathrm{~Hz}$, frequency of received analog signal ranges from $0 \mathrm{hz}$ to $40 \mathrm{~Hz}$. So, we use the low pass filter to eliminate high frequency interference. Hard filter is designed with cutting frequency $100 \mathrm{~Hz}$.

\subsubsection{Soft filter}

The soft filter uses transformation FFT (Fast Fourier Transform) to transform digital signal from time domain into frequency domain. As mentioned above, when the welding torch rotates stably at frequency $20 \mathrm{~Hz}$, the frequency spectrum of the current signal is primary in the frequency domain from $0 \mathrm{~Hz}$ to $40 \mathrm{~Hz}$, so we need to remove the signal, which has frequency greater than $40 \mathrm{~Hz}$ to obtain the necessary current. In a rotation cycle, the microcontroller will take 64 samples of the welding current signal $\mathrm{I}(\mathrm{n}),(\mathrm{n}=0, \ldots, 63)$. These samples, which

are discrete signals in time domain, are converted into frequency domain using the following formula

$$
Y(m)=\sum_{n=0}^{63} I(n)\left[\cos \left(\frac{2 \pi m n}{N}\right)-j \sin \left(\frac{2 \pi m n}{N}\right)\right],
$$

where $m=0,1,2, \ldots, 63$ and $N=64$. With a sampling rate of $f_{s}=1.28 \mathrm{kHz}$, then the frequency resolution of the analysis frequency in the FFT transformation is

$$
f_{\text {analysis }}=\frac{f_{s}}{N}=\frac{1280}{64}=20 \mathrm{~Hz} \text {. }
$$

It means that the samples $Y(m), m=0, \ldots, 63$, are analysis points of FFT transformation at $0,20,40,60,80, \ldots \mathrm{Hz}$. In addition, FFT transformation has symmetrical nature

$$
Y(m)=Y(N-m), m=0, \ldots, 31 .
$$

Hence for the signal to removed high frequency noise over $40 \mathrm{~Hz}$, we assign

$$
Y(m)=0, m=3, \ldots, 60 .
$$

Then we perform reversed FFT transformation, and obtain the welding current signal in time domain with 4 extreme points, corresponding to four points on the left, weld puddle, right, traces of welding. We can calculate the current deviation, which is input signal of the controller of the welding position. 


\subsection{Determine deviation of the torch}

In each rotation cycle, we can always determine the position of the lowest current at the center front of the $\mathrm{V}$ groove, where there is no flow of welding arc, arc height will be the largest. Second minimum in the welding cycle locate at the center rear of the $\mathrm{V}$ groove, where welding spots have formed. The maximum welding current would correspond to two extreme left and extreme right position of the torch from the centerline of the $\mathrm{V}$ groove. Orientation of the torch is always fixed along the front from left to right and to welding beam. So the order of the extreme intensity of welding current is left $\rightarrow$ front $\rightarrow$ right $\rightarrow$ rear $\rightarrow$ left ... Based on the variation of the graph function, we can identify four of these extreme values. When there are output data of the soft filter in a cycle, we consider the first two elements. If value of function is increasing, we examine the data until it decreases, then we will determine the maximum. Then we examine the data until it increases, and determine the minimum. In the process of exploring graph to find the extreme values, we observe the following principles:

- Initially, to find the maximum, we assign it is $\max 1$ then $\min 1$, then $\max 2$ and then finally $\min 2(\max 1 \rightarrow \min 1 \rightarrow \max 2 \rightarrow \min 2)$.

- Initially, to find the minimum, we assign it is $\min 1$ then $\max 2$, then $\min 2$ and then finally $\max 1(\min 1 \rightarrow \max 2 \rightarrow \min 2 \rightarrow \max 1)$.

If $\min 1<\min 2$ corresponding the torch derived from the left side of the $\mathrm{V}$-groove, $\Delta I=$ $\max 1-\max 2$. If $\min 1>\min 2$ corresponding the torch derived from the right side of the $\mathrm{V}$ groove, $\Delta I=\max 2-\max 1$. Because $\Delta I$ is always $\left(I_{\text {left }}-I_{\text {right }}\right)$, the torch is left deviation if $\Delta I$ is positive and the torch is right deviation if $\Delta I$ is negative.

\subsection{Fuzzy controller}

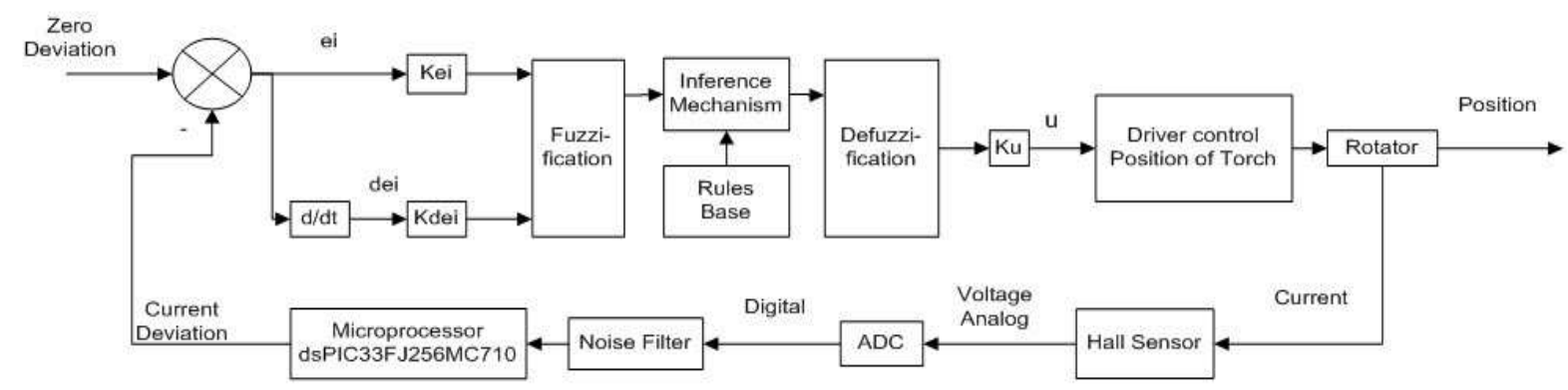

Figure 8. The principle of fuzzy tracking control system

The fuzzy controller can be divided into three parts: fuzzification, inference mechanism, and defuzzification. Fuzzification encoded input values to linguistic descriptions. Inference mechanism determined conclusions based on rules base. Finally, defuzzification converted decisions into actions or controlled values. Fig. 8 shows the process in which microprocessor get input values from hall sensor calculate controlled values by fuzzy controller. 


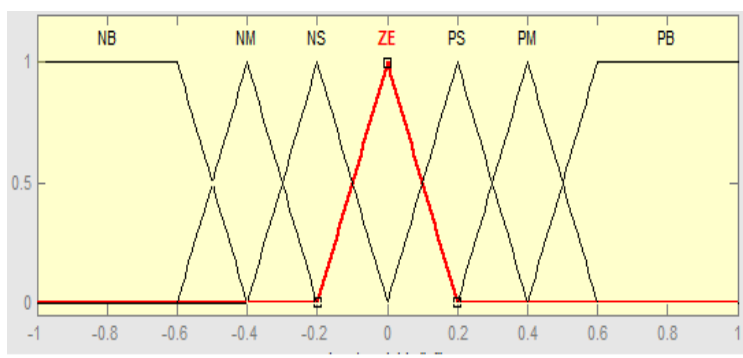

(a) Membership Functions of EI

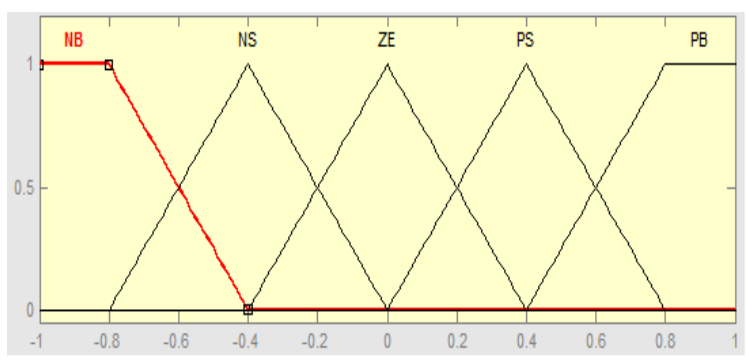

(b) Membership Functions of DEI

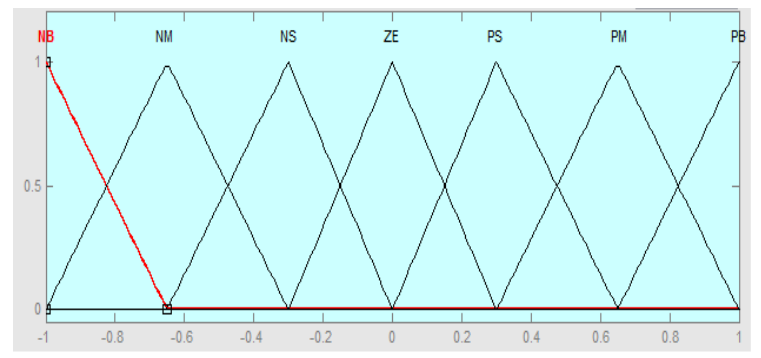

(c) Membership Functions of DISTANCE

Figure 9. Membership functions

\subsubsection{The input and output of the controller}

Two-dimensional fuzzy controller is chosen for this system. The first input signal is the deviation of average current of two haft-cycles $\left(e_{i}=I_{\text {left }}-I_{\text {right }}\right)$, when the torch on the left and right of center to the center line of the welding $\mathrm{V}$-groove. The second input signal is the differential of this deviation $d e_{i}=d\left(e_{i}\right) / d t$. The output is distance of the torch and bisector of $\mathrm{V}$-groove, which decided values of PWM and direction supplied to motor controlling position of the torch. Membership functions of the input $e_{i}$ and the output distance are negative big (NB), negative middle (NM), negative small (NS), zero (ZE), positive small (PS), positive middle (PM), and positive big (PB). And membership functions of input $d e_{i}$ are NB, NS, ZE, PS, and PB. Because output signals of fast fourier transfer (FFT) filter are fractional numbers (16 bits has ranged from -1 to 1 ), we design the range of two input i $(-1 ; 1)$, and the same range for output distance with the output scale factor, which we can adjust in the experiments. The universes of discourse the input $e_{i}$ and the output distance are divided into thirteen subnets between [-1;1]. The universe of discourse input $d e_{i}$ is divided into eleven subnets between $[-1 ; 1]$. The membership functions are set as isosceles triangle which is shown in Fig.9.

\subsubsection{Fuzzy control rules}

The fuzzy rule base consists of a group of IF-THEN control rules with two input EI, DEI and output is DISTANCE. Table.1 shows all fuzzy rules. It consists of 35 IF-THEN rules for fuzzy tracking controller:

Rule 1: If EI is NB and DEI is NB then DISTANCE is PB.

Rule 2: If EI is NB and DEI is NS then DISTANCE is PB.

Rule 3: If EI is NB and DEI is ZE then DISTANCE is PB. 
Table 1. The Fuzzy Control Rules

\begin{tabular}{|c|c|c|c|c|c|c|c|c|}
\hline \hline \multirow{2}{*}{ DISTANCE } & \multicolumn{7}{|c|}{ EI } \\
\cline { 3 - 9 } \multicolumn{1}{c|}{} & NB & NM & NS & ZE & PS & PM & PB \\
\hline \multirow{4}{*}{ DEI } & NB & PB & PB & PM & PM & ZE & NS & NM \\
\cline { 2 - 9 } & NS & PB & PB & PM & PS & ZE & NM & NB \\
\cline { 2 - 9 } & ZE & PB & PM & PS & ZE & NS & NM & NB \\
\cline { 2 - 9 } & PS & PB & PM & ZE & NS & NM & NB & NB \\
\cline { 2 - 9 } & PP & PM & PS & ZE & NM & NM & NB & NB \\
\hline
\end{tabular}

Rule 35: If EI is PB and DEI is PB then DISTANCE is NB.

The fuzzy rule base consists of IF-THEN control rules, that is If $E I=A_{i}$ and $D E I=B_{j}$ then $D I S T A N C E=C_{i j}(i=1, \ldots, 7 ; j=1, \ldots, 5)$, where $A_{i}, B_{j}$ and $C_{i j}$ are membership functions. The fuzzy relation can be expressed as

$$
R=\bigcup_{i=1, j=1}^{i=7, j=5} R_{i j}=\bigcup_{i=1, j=1}^{i=7, j=5}\left(A_{i} . B_{j} \Rightarrow C_{i j}\right) .
$$

In this paper, we use the inference rule max - product and the defuzzification method is the centre of gravity. Given input $e_{i}=x$ and $d e_{i}=y$, the output distance $=z$ can be determined. We have

$$
\mu_{R_{i j}}(z)=\left[\min \left(\mu_{A_{i}}(x), \mu_{B_{j}}(y)\right)\right] \cdot \mu_{C_{i j}}\left(z_{k}\right),
$$

where, $z_{k} \in[-1 ; 1]$ is range of output.

$k=1, \ldots, N$. (the value of $N$ belongs to calculating ability of microprocessor). Thus, we have

$$
\mu_{R}\left(z_{k}\right)=\bigcup_{i=1, j=1}^{i=7, j=5} \mu_{R_{i j}}\left(z_{k}\right)
$$

where, $U$ is maximum operation. Finally, we get

$$
z=\frac{\sum_{k=1}^{N} \mu_{R}\left(z_{k}\right) z_{k}}{\sum_{k=1}^{N} \mu_{R}\left(z_{k}\right)} .
$$

\section{EXPERIMENT}

The experiments are done to check the reliability of the received signal from the sensor and assess the possibility of using welding current signal from rotating arc sensor to control the welding robot and estimate tolerance of welding robot control problem using the fuzzy logic controller. The welding conditions were used in the experiments are shown in Table 2. The material is used in this study is low-carbon steel plates. Angle of welding line (V-groove) and direction of vertical ball screw is $45^{\circ}$. The welding current signal which is shown on Fig. 11 
FUZZY BASED WELDING SEAM TRACKING CONTROL FOR GMAW WITH ROTATING ARC SENSOR 383

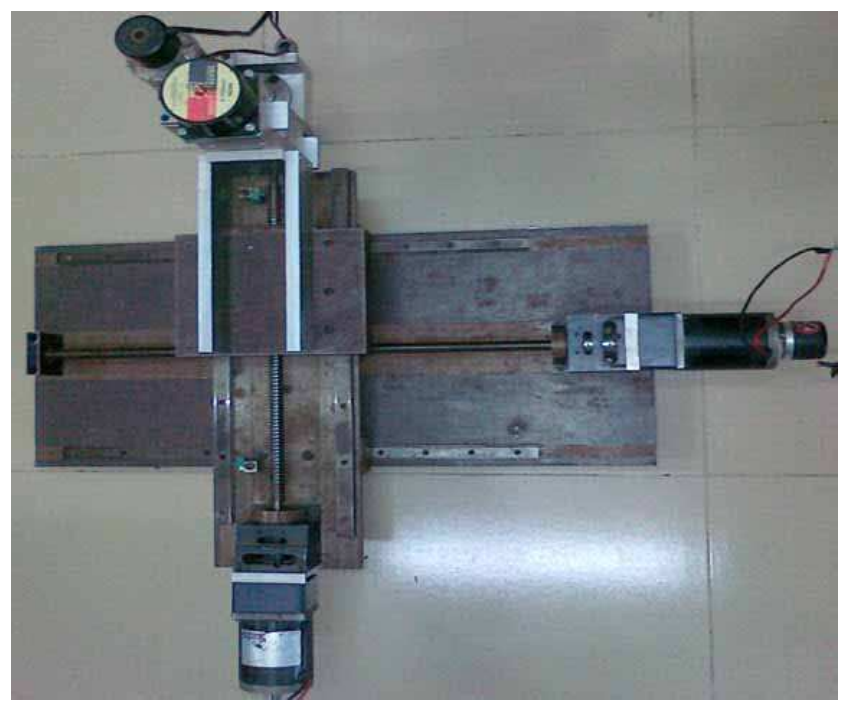

Figure 10. Experiment Model

Table 2. Welding Conditions

\begin{tabular}{|c|c|c|c|}
\hline \hline Dimensions $(\mathrm{mm})$ & $500 \times 40 \times 5$ & Electrode wire & $1,2 \mathrm{~mm}$ \\
\hline Seam geometry & V-groove & Shield gas & $\mathrm{CO}_{2}$ gas \\
\hline Thickness of base metal & $5 \mathrm{~mm}$ & Arc rotating speed & $20 \mathrm{hz}$ \\
\hline Welding voltage & $30 \mathrm{~V}$ & Rotating radius & $2,5 \mathrm{~mm}$ \\
\hline Welding speed & $6 \mathrm{~mm} / \mathrm{s}$ & Control cycle & $50 \mathrm{~ms}$ \\
\hline Wire feed speed & $95 \mathrm{~mm} / \mathrm{s}$ & & \\
\hline
\end{tabular}

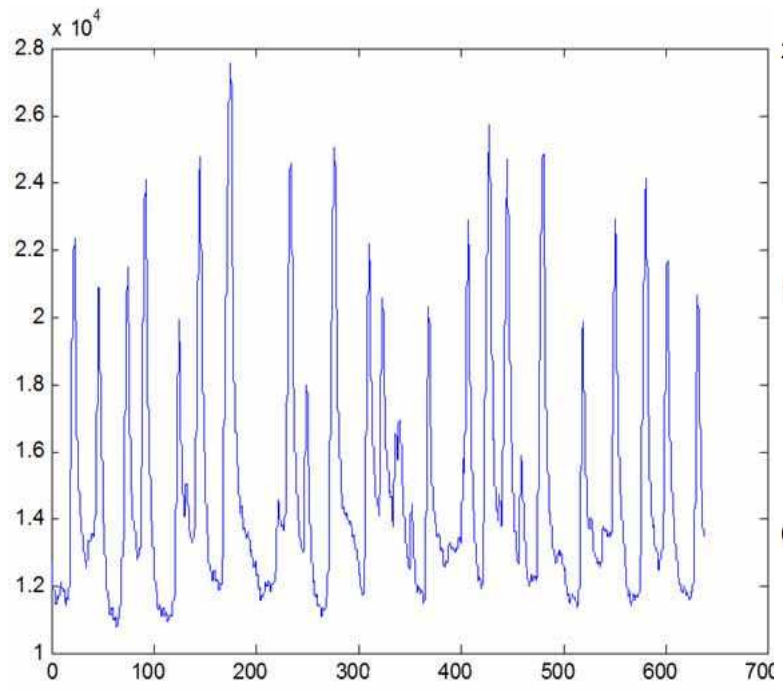

Figure 11. Signal before filtering

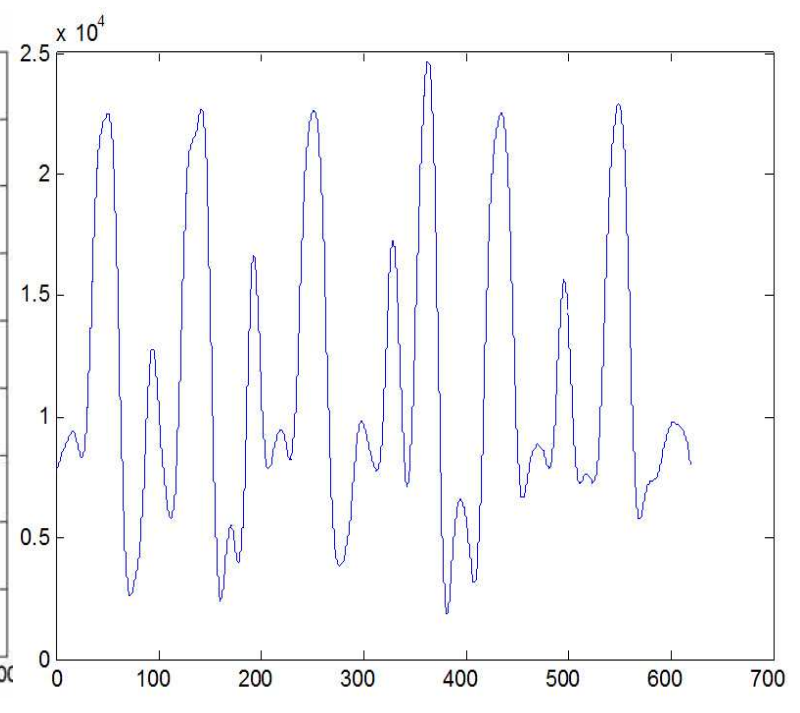

Figure 12. Filtered signal

(or Fig. 12) has many big peaks and frequency of signal is not stable. It means the current signal is affected greatly by short circuit phenomenon. Some reasons of this phenomenon are 


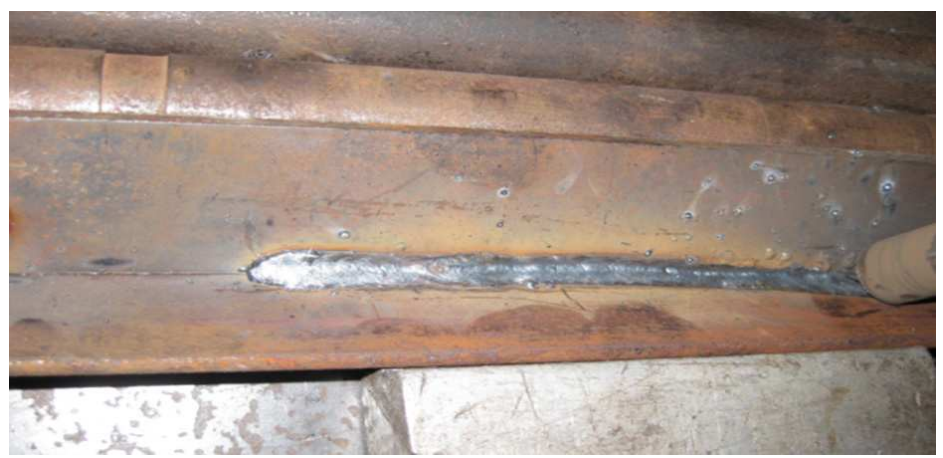

Figure 13. Result of seam tracking

followed:

- The limit of Hall sensor which was used is not suitable with maximum current of the welding power source.

- Mechanical model is not stable.

Fig.13 shows result of the fuzzy based seam tracking controller. We hope the improvement model can achieve better result and the proposed controller can be applied for straight welding line (V-groove type) in real industrial system.

\section{CONCLUSIONS}

The fuzzy controller can adapt to lots of environments. It can help sliders carry the torch to track to various profiles of welding line. Ability of the fuzzy controller has been tested by simulation but experimental control has not had good result yet because of some restrictions from the received signal from the rotating arc sensor. However, we are trying to determine and eliminate short circuit frequency and improve experiment model.

\section{REFERENCES}

[1] Pan Jiluan, Arc welding Control, Woodhead Publishing Limited, 2003.

[2] Yong-Hua Shi, Ji-Tae Kim and Suck-Joo Na, "Signal Patterns of High Speed Rotational Arc Sensor for Gas Metal Arc Welding", Sensors for Industry Conference Houston, Texas, USA, 8-10 February 2005.

[3] Gun-You Lee, Myung-Suck Oh and Sang-Bong Kim, Development of a high speed rotating arc sensor system for tracking complicate curved fillet welding lines, International Journal of the Korean Society of Precision Engineering Vol. 4 (6) (November 2003).

[4] Jianping Jia and Hua Zhang, Zhenyu Xiong, A fuzzy tracking control system for arc welding based on rotating arc sensor, Proceedings of the 2006 IEEE International Conference on Information Acquisition, Weihai, Shandong, China, August 20 - 23, 2006.

Received on October 25 - 2010 